\title{
INTERNALISASI NILAI-NILAI AKHLAQUL KARIMAH DALAM KEHIDUPAN SEHARI-HARI SISWA SD NEGERI 1 CIBUGEL
}

\author{
Aidil Syahfitra ${ }^{1)}$ M. Asro ${ }^{2)}$ \\ ${ }^{1)}$ Pendidikan Agama Islam, Fakultas Tarbiyah dan Keguruan, UIN Sunan Gunung Djati Bandung, e-mail : \\ aidilsyahfitra21@gmail.com \\ ${ }^{2)}$ Fakultas Syariah dan Hukum UIN Sunan Gunung Djati Bandung, e-mail : muhammadasro@uinsgd.ac.id
}

\begin{abstract}
Abstrak
Pendidikan dapat diartikan sebagai sebuah bentuk untuk memajukan kehidupan negara, kesejahteraan negara, dan menjadikan negara yang bermoral tinggi, beretika, dan berbudaya sosial yang mulia. Pendidikan dilakukan demi berkembangnya potensi peserta didik agar menjadi manusia yang beriman dan bertakwa kepada Tuhan Yang Maha Esa, berakhlak mulia, sehat, berilmu, cakap, kreatif, mandiri, dan menjadi warga negara yang demokratis serta bertanggung jawab. Pengabdian ini merupakan pengandian dalam bentuk penelitian kualitatif deskriptif, data-data diperoleh melalui observasi, wawancara, dokumentasi, dan sosialisasi. Analisis data menggunakan reduksi data, untuk mendeskripsikan Internalisasi Nilai-Nilai Akhlaqul Karimah dalam Kehidupan Sehari-hari Siswa SD Negeri 1 Cibugel Desa Jayamekar Kecamatan Cibugel Kabupaten Sumedang. Penelitian ini bertujuan untuk memberikan pemahaman kepada siswa akan pentingnya akhlakuk karimah dalam kehidupan sehari-hari baik akhlak kepada Allah, orang tua, guru, teman sebaya maupun akhlak-akhlak yang berkaitan dengan kehidupan sehari-hari. Selain itu juga pengabdian ini juga bertujuan untuk menganalisa bagaimana tingkat moralitas siswa sebagai bahan pertimbangan untuk menilai kualitas akhlak generasi-generasi penerus bangsa, baik itu di masa sekarang atau nanti di masa yang akan datang. Hasil penelitian ini menunjukkan bahwa siswa memiliki antusias dan partisipasi yang tinggi menjadi insan yang lebih baik hal ini terbukti secara implisit dalam kegiatan sosialisasi yang telah dilaksanakan, yang mana hal ini secara tersirat menunjukkan perkembangan akhlak siswa dalam menghargai orang lain.
\end{abstract}

Kata Kunci: Akhlak Terpuji, internalisasi nilai-nilai, pendidikan.

\begin{abstract}
Education can be interpreted as a form to advance the life of the country, the welfare of the country, and to make a state of high moral, ethical, and noble social culture. Education is carried out for the development of the potential of students to become human beings who believe in and fear God Almighty, have good character, be healthy, knowledgeable, capable, creative, independent, and become democratic and responsible citizens. This service is encoded in the form of descriptive qualitative research, data obtained through observation, interviews, documentation, and socialization. Data analysis uses data reduction, to describe the internalization of the values of morality in the daily life of students of SD Negeri 1 Cibugel, Jayamekar Village, Cibugel District, Sumedang District. This study aims to provide students with an understanding of the importance of moral behavior in daily life, both morals to God, parents, teachers, peers and morals related to daily life. In addition, this service also aims to analyze how the level of morality of students as a material consideration for assessing the moral quality of future generations of the nation, both in the present or future in the future. The results of this study indicate that students have high enthusiasm and participation to be better human beings. This is proven implicitly in the socialization activities that have been carried out, which implicitly indicate the development of students' morals in respecting others.
\end{abstract}

Keywords: Education. Internalization of values, praiseworthy 


\section{PENDAHULUAN}

Pendidikan adalah upaya sadar yang dilakukan untuk mencerdaskan manusia, menjadikan manusia lebih menjadi manusia yang seutuhnya, melalui pendidikan diharapkan mampu menciptakan generasi penerus bangsa yang cakap, cerdas, dan berilmu. Pendidikan dapat diartikan sebagai sebuah bentuk untuk memajukan kehidupan negara, kesejahteraan negara, dan menjadikan negara yang bermoral tinggi, beretika, dan berbudaya sosial yang mulia.

Selain itu pendidikan berfungsi sebagai sebuah jembatan untuk menghantarkan pelaku di dalamnya menjadi orang yang berjiwa besar, berkararter yang mulia, dan berbudi pekerti yang luhur. Pendidikan berdasarkan UU No. 20 tahun 2003 bertujuan untuk berkembangnya potensi peserta didik agar menjadi manusia yang beriman dan bertakwa kepada Tuhan Yang Maha Esa, berakhlak mulia, sehat, berilmu, cakap, kreatif, mandiri, dan menjadi warga negara yang demokratis serta bertanggung jawab. Akan tetapi, seiring berkembangnya masa dimana era globalisai ini banyak menggiring masyarakat Indonesia sedikit demi sedikit keluar dari koridor jati diri negara yang sejatinya kental akan budi luhur ketimuran, sekarang mengarah kearah budaya barat.

Dewasa ini problem yang sering di alami oleh peserta didik adalah masalah-masalah yang berkaitan dengan akhlak mereka seperti, ugalugalan di luar jam sekolah bahkan di rana sekolah dan mirisnya lagi di dalam kelas ketika proses mengajar dan belajar sedang berlangsung. Selain itu masalah akhlak yang banyak terjadi di rana pelajar bangsa ini yaitu masalah perilaku tercela yang diindikasikan seperti menonton film forno, merokok, tawuran, bolos sekolah demi bermain game bahkan ada yang melakukannya demi untuk pacaran.

Dari semua masalah yang dipaparkan di atas masalah yang paling serius, yang merupakan pekerjaan rumah terbesar pemerintah dalam hal ini menteri pendidikan dan kebudayaan nasional yaitu masalah yang berkaitan dengan akhlak para peserta didik kepada guru. Permasalahan apa yang terjadi ? permasalahan yang terjadi pada rana ini banyaknya para pelajar yang menantang guru, melotot kepada guru, menjawab guru ketika dinasehati, bahkan mirisnya ada diantara kasus yang terjadi siswa mengancam gurunya dengan senjata tajam bahkan membunuh.

Hal ini sangat berbeda jauh dengan identitas bangsa yang sangat menghargai dan menghormati manusia sebagai raja di muka bumi. Sangat miris, pendidikan yang pada intinya ialah bertujuan untuk membangun pribadi yang agamis, dimana setiap individu dapat menemukan siapa dia sesungguhnya, arti dan tujuan hidupnya melalui interaksi dengan alam, lingkungan dan nilai-nilai spritualitas atau mendidikan aspek kognitif, afektif, dan psikomotorik. Akan tetapi pada kenyataannya hanya aspek kognitif saja yang membuat anak membaur dengan lingkungannya. ${ }^{1}$

Bahkan, pola pikir dan kebiasaan para pelajar masa sekarang semakin jauh dari tujuan mulia pendidikan bangsa ini oleh perilaku-perilaku penyimpangan sosial seperti free sex, aborsi, homoseksual, lesbian, dan sebagainya. ${ }^{2}$ Yang mana hal ini disebabkan oleh pergaulan bebas. Bahkan,

${ }^{1}$ Agus Zaenul Fitri, Pendidikan Karakter Berbasis Nilai dan Etika di Sekolah (Yogyakarta: Ar-Ruzz Media, 2012), hlm. 10

2 Ibid. 
siswa diberikan fasilitas untuk mencoba yang akan berakhir menjadi kebiasaannya, apa yang telah mereka peroleh dalam kehidupan sehari-hari. ${ }^{3}$

Problem pendidikan yang diamali bangsa Indonesia saat ini bukan problem yang berkenaan dengan persoalan kualitas sumber daya manusianya, tetapi lebih mengarah kepada sistem dan lingkungan pendidikan yang belum mampu menjadi wadah bagi perkembangan peserta didik secara ideal. ${ }^{4}$ Secara pemikiran, pembelajaran akidah akhlaq di madrasah perlu diarahkan dan ditujukan kepada ajaran Islam yang rahmatan lil 'alamin. Pendekatan pembelajaran akidah akhlaq di madrasah sangatlah diarahkan dan dilakukan secara kontekstual, yaitu materi yang disesuaikan dengan upaya untuk menjadikan siswa yang berakhlak baik dan untuk memahami dan mendiskusikan materi pelajaran. Bahkan, siswa. ${ }^{5}$

Maka dari itu perlulah bagi peneliti untuk melakukan pengabdian kepada masyarakat dalam hal ini kepada lembaga SDN 1 Cibugel untuk berbagi pengalaman, dan mencari pengalaman mengenai proses internalisasi nilai-nilai akhlakul karimah. Penulis memberikan sebuah tulisan yang singkat ini sebagai bentuk usaha untuk memberikan solusi mengenai masalah-masalah di atas, yang mana tulisan ini berjudul “ Internalisasi Nilai-Nilai Akhlaqul Karimah dalam Kehidupan Sehari-hari Siswa SD Negeri 1 Cibugel"

3 Sutrisno, Pembaharuan dan Pengembangan Pendidikan Islam, (Yogyakarta, Fadilatama, 2011), hlm. 85.

4 Zuhari, dkk. Metodik Khusus Pendidikan Agama; Dilengkapi dengan Sistem Modul dan Permaianan Simulasi (Surabaya: Biro Ilmiah Fakultas Tarbiyah IAIN Sunan Ampel Surabaya dan Usaha Offset Printing, 1983), hlm. 27.

${ }^{5}$ Sutrisno, Pembaharuan dan Pengembangan Pendidikan Islam, (Yogyakarta, Fadilatama, 2011), hlm. 85.
Perumusan masalah yang peneliti ajukan atau yang akan dibahas adalah :'Bagaimana tahapan-tahapan dan hasil internalisasi nilai-nilai akhlakul karimah di SDN 1 Cibugel ?. Tujuan penelitian ini adalah untuk mengetahui tahapantahapan dan hasil internalisasi nilai-nilai akhlakul karimah di SDN 1 Cibugel.

Berikut sebagai bahan pertimbangan dan pengayaan mengenai pengabdian, peneliti menyajikan kajian teoritik yang melandasi penelitian ini :

a. Pengertian Pendidikan

Di dalam UU No.20 tahun 2003 dijelaskan bahwa makna pendidikan adalah usaha dasar dan terencana untuk mewujudkan suasana belajar dan proses pembelajaran agar peserta didik secara aktif mengembangkan potensi dirinya untuk memiliki kekuatan spiritual keagamaan, pengendalian diri, kepribadian, kecerdasan, akhlak mulia, serta keterampilan, yang diperlukan dirinya, masyarakat, dan Negara. ${ }^{6}$

Ki Hajar Dewantara sebagai bapak pendidikan Nasional Indonesia berkata bahwa : "Pendidikan merupakan tuntunan tentang bagaimana perkembangan kehidupan anak, maksudnya pendidikan adalah wadah yang menuntun adapun maksud dari pendidikan yaitu mengarahkan segala potensi dan fitrah yang Allah berikan pada anak-anak, agar mereka dapat mencapai keselamatan dan kebahagiaan. ${ }^{7}$

\footnotetext{
${ }^{6}$ Haryanto, 2012: dalam artikel "pengertian pendidikan menurut para akhli http://belajarpsikologi. com/pengertianpendidikan-menurut-ahli/ diakes pada tanggal 22 september 2019

${ }^{7}$ Ibid.
} 
b. Tujuan Pendidikan

Sebagaimana telah dijelaskan di atas bahwa berdasarkan UU No. 20 Tahun 2003 dijeskan bahwa tujuan nasional pendidikan adalah untuk mengembangkan potensi peserta didik agar menjadi manusia yang beriman dan bertakwa kepada Tuhan Yang Maha Esa, berakhlak mulia, sehat, berilmu, cakap, kreatif, mandiri, dan menjadi warga negara yang demokratis serta bertanggung jawab.

c. Pengertian akhlak

Dalam makna umum akhlak disamakan maknanya dengan budi pekerti, kesusilaan, sopan santun dalam bahasa Indonesia, dan juga semakna dengan arti kata moral, ethic dalam bahasa inggris. Manusia akan menjadi sempurna jika mempunyai akhlak terpuji serta menjauhkan segala akhlak tercela. ${ }^{8}$

Adapun secara istilah, akhlak adalah nilai- nilai yang menuntun pola sikap dan tindakan manusia di muka bumi. Nilai-nilai yang dimaksud adalah ajaran Islam, dengan AlQur'an dan Sunnah Rasul sebagai dasar nilainya serta ijtihad sebagai sarana berfikir islami. Pola sikap dan tindakan yang dimaksud mencakup pola-pola hubungan dengan Allah, sesama manusia (termasuk dirinya sendiri), dan dengan alam. ${ }^{9}$

d. Tujuan Pendidikan Akhlak

Tujuan pendidikan akhlak dalam Islam adalah agar manusia berada dalam kebenaran dan senantiasa berada di jalan yang lurus, jalan

8 Dr. Mansur, MA, Pendidikan Anak Usia Dini dalam Islam, (Yogyakarta: Pustaka Pelajar, 2009) cet. 3, hlm.221

9 Muslim Nurdin dkk, Moral dan Kognisi Islam, (Bandung: CV Alfabeta, 1995), ed. 2. hlm. 209 yang telah digariskan oleh Allah swt. ${ }^{10}$ Inilah yang akan mengantarkan manusia kepada kebahagiaan di dunia dan di akhirat. Dan tujuan ini semakna dan sesuai dengan tujuan Allah subhanahu wa ta'ala mengurus seorang Rasul Muhammad shallallaahu 'alaihi wa sallam yang mana tiada lain dan bukan untuk membenarkan akhlak manusia.

\section{METODOLOGI PENGABDIAN}

Metodologi yang digunakan di dalam pengabdian ini secara umum menggunakan pendekatan atau metode penelitian kualitatif deskriptif, yang mana data diperoleh melalui tiga jalan atau empat tahap yaitu, observasi, wawancara, dokumentasi, dan sosialisasi. Berikut adalah penjelasan dari tahap-tahap yang dilakukan :

a. Observasi : kegiatan ini dilakukan selama waktu pengabdian berlangsung, yang mana peneliti melakukan pengamatan secara langsung bagaimana akhlak siswa dan cara guru menanamkan nilai-nilai akhlak

b. Wawancara : wawancara dilakukan secara langsung kepada kepala sekolah dan beberapa guru, mengenai proses penanaman akhlak kepada siswa.

c. Dokumentasi : tahap ini yaitu mengumpulkan data-data siswa melalui progres perkembangan akhlak siswa yang dilihat dari nilai afektifnya.

d. Sosialisasi : peneliti pada tahap ini melakukan sosialisai secara langsung kepada objek kajian pengabdian dengan memberikan pemahaman kepada siswa mengenai akhlak yang terpuji dan bahaya akhlak yang tercela.

10 Aboebakar Aceh, Pendidikan Sufi Sebuah Karya Mendidik Akhlak Manusia Karya Filosof Islam di Indonesia, (Solo: CV. Ramadhani, 1991, cet. 3, hlm. 12 
Hasil dari keempat tahap di atas, selanjutnya dianaliss menggunakan teknik Analisis data menggunakan reduksi data, yang mana bertujuan untuk mendeskripsikan Internalisasi Nilai-Nilai Akhlaqul Karimah dalam Kehidupan Sehari-hari Siswa SD Negeri 1 Cibugel Desa Jayamekar Kecamatan Cibugel Kabupaten Sumedang.

\section{HASIL DAN PEMBAHASAN}

\section{Definisi Internalisasi Nilai}

Internalisasi nilai adalah proses implementasu nilai menjadi bagian dari diri seseorang. ${ }^{11}$ Secara jelas Soedijarto menjelaskan bahwa proses tersebut tercipta dari pendidikan nilai dalam pengertian yang sesungguhnya, yaitu terciptanya suasana, lingkungan dan interaksi belajar mengajar yang memungkinkan terjadinya proses sosialisasi dan internalisasi nilai-nilai. ${ }^{12}$ Chabib Thoha menuturkan, internalisasi nilai adalah cara dalam pendidikan nilai dalam menyalurkan nilai-nila yang objeknya adalah sampai pada interpensi nilai yang menyatu dalam karakter peserta didik. ${ }^{13}$ Melalui internalisasi nilai kepribadian peserta didik dapat mewujudkan suasana yang terkondisikan dalam proses pembelajaran. Secara sederhana internalisasi adalah proses terjadi dari sosialisai, adaptasi, dan erkulturasi (pembudayaan).

\section{Unsur-unsur dalam Internalisasi Nilai}

Menurut Majid Irsan al-Kailany yang dikutip Maksudin, penyebarluasan nilai yang

\footnotetext{
${ }^{11}$ Soedijarto, Menuju Pendidikan Nasional Yang Relevan Dan Bermutu, (Jkarta: BalaiPustaka, 2003), Cet. 4, hlm. 14.

12 Ibid. Hlm. 128

13 Chabib Thoha, Kapita Selekta Pendidikan Islam, (Yogyakarta: Pustaka Pelajar, 2006), hlm. 87-93.
}

dapat ditemukan secara kolektif melalui persamaan, pembiasaan, tempat-tempat umum, pergaulan yang baik dan benar sesuai kewajiban warga masyarakat.

Dan juga nilai yang diperoleh melalui media yang digunakan untuk mencapai tujuan, misalnya nilai susunan percakapan, nilai kemasyarakatan, dan nilai-nilai akhlak yang bermacam-macam, serta nilai moral, yaitu nilai yang ditentukan berdasarkan tujuan dan perbuatan yang benar. ${ }^{14}$ Sehingga dari kedua unsur ini akan menghasilkan proses adaptasi peserta didik dalam mentransformasi nilai-nilai yang dia peroleh sebagai sebuah karakter dalam dirinya.

\section{Tahapan-tahapan Internalisasi Nilai}

Sebagaimana telah diterangkan sebelumnya pada bagian metodologi penilitian bahwa pengabdian ini secara umum menggunakan pendekatan atau metode penelitian kualitatif deskriptif, yang mana data diperoleh melalui tiga jalan atau empat tahap yaitu, observasi, wawancara, dokumentasi, dan sosialisasi. Berikut adalah penjelasannya :

a. Observasi : kegiatan ini dilakukan selama waktu pengabdian berlangsung, yang mana peneliti melakukan pengamatan secara langsung bagaimana akhlak siswa dan cara guru menanamkan nilai-nilai akhlak

b. Wawancara : wawancara dilakukan secara langsung kepada kepala sekolah dan beberapa guru, mengenai proses penanaman akhlak kepada siswa.

${ }^{14}$ Maksudin, Pendidikan Nilai Sistem Boarding School di SMP Islam Terpadu Abu Bakar (Yogyakarta: Pps UIN Sunan Kalijaga, 2008), hlm. 52. 
c. Dokumentasi : tahap ini yaitu mengumpulkan data-data siswa melalui progres perkembangan akhlak siswa yang dilihat dari nilai afektifnya.

d. Sosialisasi : peneliti pada tahap ini melakukan sosialisai secara langsung kepada objek kajian pengabdian dengan memberikan pemahaman kepada siswa mengenai akhlak yang terpuji dan bahaya akhlak yang tercela.

Hasil dari keempat tahap di atas, selanjutnya dianaliss menggunakan teknik Analisis data menggunakan reduksi data, yang mana bertujuan untuk mendeskripsikan Internalisasi Nilai-Nilai Akhlaqul Karimah dalam Kehidupan Sehari-hari Siswa SD Negeri 1 Cibugel Desa Jayamekar Kecamatan Cibugel Kabupaten Sumedang.

Mengenai tahapan internalisasi nilai ini, Soedijarto menyatakan bahwa bila nilai yang akan ditanamkan dimaksudkan untuk sepenuhnya menjadi bagian sistem kepribadian setiap anak didik, maka tahap pengenalan dan pemahaman, penerimaan dan pengintegrasian, ketiga-tiganya wajib ditempuh. Sedangkan tiga tahap tersebut merupakan teori yang dikemukakan oleh Krathwhol dan telah dikerucutkan oleh Soedijarto. ${ }^{15}$ Berikut adalah tahapan-tahapan dalam internalisai nilai :

a. Tahap Pengenalan dan Pemahaman

Pada tahap pengenalan dan pemahaman ini peserta didik mulai tertarik memahami dan menghargai pentingnya nilai-nilai akhlaqul karimah bagi dirinya, yang mana proses ini ditemukan atau diberikan dalam proses kegiatan mengajar dan belajar sedang berlangsung.

Selain itu juga, pada tahap ini peserta didik dapat mengenal nilai-nilai akhlakul karimah melalui preses interaksi sosial non kelas yang dia lakukan kepada teman sebaya, guru, dan pihak sekolah secara umum. Sehingga pada tahap ini diharapkan siswa dapat memahami dirinya senidri bahwa dia butuh akan akhlakul karimah di dalam kehidupannya seharihari baik itu kepada Allah, Orang lain (keluarga, guru, dan teman), kepada alam, dan adab-adab kebiasaan dalam kehidupana pada umumnya seperti tidur, makan, berkendara dan sebagainya.

b. Tahap Penerimaan

Agar suatu nilai dapat diterima, diperlukan suatu pendekatan belajar yang merupakan proses sosial, yaitu pendekatan yang memungkinkan pelajar merasakan diri dalam konteks hubungannya dengan lingkungan, bukan suatu proses yang menempatkan pelajar dalam suatu jarak dengan yang sedang dipelajari.

Sarana-sarana tersebut memiliki nilai penting dalam tahap penerimaan ini. Hal-hal yang menjadisarana dalam proses internalisasi nilai-nilai akhlaqul karimahkhususnya tahappenerimaan ini kegiatan keagamaan, tata tertib (baik tata tertibguru, karyawan dan siswa), lingkungan benda, peneladanan, pembiasaan sertadorongan-dorongan atau pemberian motivasi melalui pemberian penghargaandan pujian terhadap siswa untuk mengamalkan nilai-nilai akhlaqul 
karimah yangtelah dipahami dan mulai diterima.

c. Tahap Pengintegrasian

Pada tahap ini seorang pelajar mulai memasukkan nilai kedalam keseluruhan sistem nilai yang dianutnya.Tahap pengintegrasian ini merupakan hasil dari tahap-tahap sebelumnya, jadi tahap ini ditentukan oleh tahap pengenalan dan pemahaman dan tahap penerimaan.

4. Pendekatan dalam internalisasi nilai-nilai akhlaqul karimah

Pendekatan yang dilakukan sebagai bentuk internalisasi nilai-nilai akhlaqul karimah pada siswa SDN 1 Cibugel Desa Jayamekar, Kecamatan Cibugel, Kabupaten Sumedang, menggunakan pendekatan penelitian kualitatif deskriptif yang dianalisa dengan tehnik reduksi data melalui empat tahapan sebagai berikut :

a. Observasi : kegiatan ini dilakukan selama waktu pengabdian berlangsung, yang mana peneliti melakukan pengamatan secara langsung bagaimana akhlak siswa dan cara guru menanamkan nilai-nilai akhlak

b. Wawancara : wawancara dilakukan secara langsung kepada kepala sekolah dan beberapa guru, mengenai proses penanaman akhlak kepada siswa.

c. Dokumentasi : tahap ini yaitu mengumpulkan data-data siswa melalui progres perkembangan akhlak siswa yang dilihat dari nilai afektifnya. d. Sosialisasi : peneliti pada tahap ini melakukan sosialisai secara langsung kepada objek kajian pengabdian dengan memberikan pemahaman kepada siswa mengenai akhlak yang terpuji dan bahaya akhlak yang tercela.

\section{Faktor Pendukung dan Penghambat}

a. Faktor Pendukung

Berikut adalah beberapa point yang menjadi faktor pendukung usaha internalisasi nilai-nilai akhlaqul karimah di SDN 1 Cibugel, Desa Jayamekar, Kecamatan Cibugel, Kabupaten Sumedang

1) Sekolah yang terletak di pedesaan yang masih asri, yang masih menjunjung nilai-nilai budi pekerti luhur.

2) Kegiatan keagamaan, lingkungan yang interaktif, lingkungan sekolah yang bisa dikatakan semi-tradisional, serta pembiasaan karakter-karakter budi pekerti luhur yang agamis

3) Mayoritas orang tua siswa yang berprofesi sebagi petani yang notabene menerapkan hidup sederhana kepada anaknya dan seringnya interaksi antara orang tua dan anak secara kondusif.

4) Berkembangnya disiplin ilmu, lingkusangan sekolah yang masih asri dan lain sebaginya, membuat mudahnya untuk menerapkan berbagai pendekatan, metode dan model dalam upaya internalisasi nilainilai akhlaqul karimah kepada siswa. 
b. Faktor Penghambat

Berikut adalah beberapa point yang menjadi faktor pendukung usaha internalisasi nilai-nilai akhlaqul karimah di SDN 1 Cibugel, Desa Jayamekar, Kecamatan Cibugel, Kabupaten Sumedang:

1) Tingkatan pemahaman siswa yang beranekaragam atau beda antara siswa yang satu dan yang lain, menyebabkan terhambatnya proses internalisasi ini terjadi karena butuh menggunakan beberapa metode, pendekatan, dan model. Sehinggu membutuhkan waktu yang lama

2) Karena jarak SDN 1 Cibegul berada jauh dari dinas pendidikan, menyebabkan kurangnya sarana dan prasarana yang menjadi pendukung dan mempermudah dalam menyampaikan hal-hal yang menjadi fokus internalisasi nilai-nilai akhlaqul karimah. Seperti infokus dan lain sebagainya.

\section{Ucapan Terima Kasih}

Pada kesempatan ini, saya ingin menyampaikan ucapan terima kasih kepada:

1. Orang tua saya yang senantiasa memberikan dukungan do'a dan motivasi

2. Bapak Prof. Dr. H. Mahmud, M.Si. selaku Rektor UIN SGD Bandung

3. Bapak Dr. H. Ramdani Wahyu Sururie, M.Ag., M.Si. selaku Kepala Pusat Pengabdian kepada Masyarakat (PkM) UIN SGD Bandung
4. Dosen Pembimbing Lapangan, Bapak M. Asro, S.Ag, MH yang telah banyak membimbing dan mengarahkan selama kegiatan KKN

5. Bapak Idi Kusnadi selaku Kepala Desa Jayamekar serta jajaran perangkat desa yang telah menerima dan bekerjasama menjalankan program pemberdayaan dan pengabdian masyarakat.

6. Bapak Ujang Sutarman selaku Kepala Dusun Simpaywargi serta jajaran baik itu dikalangan RW maupun RT yang telah memberikan dukungan selama menjalankan program KKN.

7. Pak Udin, Pak Ba'i, Pak Ajum, dan tetangga yang telah menerima kami laiknya keluarga sendiri.

8. Kawan-kawan KKN kelompok 42 yang senantiasa membantu dan menjadi partner terbaik selama kegiatan $\mathrm{KKN}$.

9. Pihak-pihak lain yang terlibat dalam mensukseskan kegiatan KKN SISDAMAS 2019 di Desa Jayamekar

\section{PENUTUP}

\section{Kesimpulan}

Hasil penelitian ini menunjukkan bahwa siswa memiliki antusias dan partisipasi yang tinggi menjadi insan yang lebih baik hal ini terbukti secara implisit dalam kegiatan sosialisasi yang telah dilaksanakan, yang mana hal ini secara tersirat menunjukkan perkembangan akhlak siswa dalam menghargai orang lain. Hasil penelitian ini diperoleh melalui empat tahapan yang dilakukan yaitu sebagai berikut :

a. Observasi : kegiatan ini dilakukan selama waktu pengabdian berlangsung, yang mana peneliti melakukan pengamatan secara 
langsung bagaimana akhlak siswa dan cara guru menanamkan nilai-nilai akhlak

b. Wawancara : wawancara dilakukan secara langsung kepada kepala sekolah dan beberapa guru, mengenai proses penanaman akhlak kepada siswa.

c. Dokumentasi : tahap ini yaitu mengumpulkan data-data siswa melalui progres perkembangan akhlak siswa yang dilihat dari nilai afektifnya.

d. Sosialisasi : peneliti pada tahap ini melakukan sosialisai secara langsung kepada objek kajian pengabdian dengan memberikan pemahaman kepada siswa mengenai akhlak yang terpuji dan bahaya akhlak yang tercela.

\section{DAFTAR PUSTAKA}

Zaenul Fitri, Agus. 2012. Pendidikan Karakter Berbasis Nilai dan Etika di Sekolah Yogyakarta: Ar-Ruzz Media.

Sutrisno. 2011. Pembaharuan dan Pengembangan Pendidikan Islam. Yogyakarta : Fadilatama.

Zuhari. dkk. 1983. Metodik Khusus Pendidikan Agama; Dilengkapi dengan Sistem Modul dan Permaianan Simulasi. Surabaya: Biro Ilmiah Fakultas Tarbiyah IAIN Sunan Ampel Surabaya dan Usaha Offset Printing.

Haryanto.2012. : dalam artikel "pengertian pendidikan menurut para akhli”. http://belajarpsikologi. com/pengertianpendidikan-menurut-ahli/ diakes pada tanggal 22 september 2019

Mansur. 2009. Pendidikan Anak Usia Dini dalam Islam. Yogyakarta: Pustaka Pelajar.

Nurdin, Muslim, dkk. 1995. Moral dan Kognisi Islam. Bandung: CV Alfabeta.

Aceh, Aboebakar. 1991. Pendidikan Sufi Sebuah Karya Mendidik Akhlak Manusia Karya Filosof Islam di Indonesia. Solo: CV. Ramadhani.

Soedijarto. 2003. Menuju Pendidikan Nasional Yang Relevan Dan Bermutu. Jakarta: BalaiPustaka
Thoha, Chabib. 2006. Kapita Selekta Pendidikan Islam. Yogyakarta: Pustaka Pelajar.

Maksudin. 2008. Pendidikan Nilai Sistem Boarding School di SMP Islam Terpadu Abu Bakar. Yogyakarta: Pps UIN Sunan Kalijaga. 